\title{
Investigation of Bone Allografts Representing Different Steps of the Bone Bank Procedure Using the CAM-Model
}

\author{
Philipp Holzmann ${ }^{1}$, Eugenia Niculescu-Morzsa ${ }^{1}$, Hannes Zwickl ${ }^{1}$, Florian Halbwirth ${ }^{1}$, \\ Monika Pichler ${ }^{2}$, Michael Matzner ${ }^{2}$, Florian Gottsauner-Wolf ${ }^{3}$ and Stefan Nehrer ${ }^{1}$ \\ ${ }^{1}$ Center for Regenerative Medicine, Danube University Krems, Austria; ${ }^{2}$ Cells+ Tissuebank Austria, Arthro Kinetics, Krems, \\ Austria; ${ }^{3}$ Department for Orthopedic Surgery, County Hospital Krems, Austria
}

\begin{abstract}
Summary
Bone grafting is commonly used to treat large bone defects. Since autografts are limited and frequently associated with postoperative donor morbidity, allografts from bone banks are often used. However, vascularisation of the allograft is often impaired, resulting in inadequate bone healing and functional graft failure. In bone bank processing, tissue is stored at $-80^{\circ} \mathrm{C}$ and subsequently subjected to a harsh multi-step cleaning and sterilisation procedure to prevent immune rejection or transmission of diseases.

To determine which step of this procedure diminishes the ability of allografts to induce or promote vascularisation, we used the chick chorioallantoic membrane (CAM) model to monitor the vascular reaction to sample bone chips representing the respective procedural steps. The CAM model monitors the angiogenic potency of xenogeneic and, hence, potentially immunogeneic materials (e.g. cells, tissues, tissue-engineered matrices). Due to the chicken embryo's lack of a fully functional immune system, it provides test conditions that are analogous to immunologically incompetent mice and is a well-suited alternative to their use.

Bone chips were placed onto the CAM, and vascular reactions were quantified by image analysis after $48 \mathrm{~h}$ incubation. The vascular reaction was most pronounced to fresh, untreated bone chips that had been kept at $+2{ }^{\circ} \mathrm{C}$ prior to the experiment. Surprisingly, storage of bone samples at $-80^{\circ} \mathrm{C}$ was sufficient to drastically reduce the vascular reaction. Consistent with this, samples representing different stages of the subsequent procedure showed similarly low vascular indices.
\end{abstract}

Keywords: bone, allograft, angiogenesis, chorioallantoic membrane (CAM), bone bank

\section{Introduction}

Massive bone loss as a result of trauma, osteomyelitis, tumour surgery or osteolysis after arthroplasty is a challenging problem in orthopaedic practice. A common treatment option is to fill the defective sites with bone transplants of either auto- or allogeneic origin, which ideally assist the bone healing and regeneration process (Finkemeier, 2002; Gross et al., 1993; Huo et al., 1992). Since fresh autografts are available in only limited number and size and their use is associated with postoperative donor morbidity and extended surgical time, allografts supplied by bone banks are most commonly used instead (Aro and Aho, 1993). The latter primarily provide an acellular mineralised matrix for bone regeneration by osteoconduction. For structural and functional integration, however, the allograft has to become colonised by cells and vascularised for the formation of new bone tissue and its nutrition, respectively. Hence, a key function of grafts is to afford bone formation by facilitating or stimu- lating the migration of mesenchymal cells and the ingrowth of host blood vessels into the matrix (Carmeliet, 2004). The latter is vital for proliferation and differentiation of precursor cells to osteoblastic cells and for the synthesis of an osteogenic matrix (Probst and Spiegel, 1997).

In contrast to autografts, allografts are immunogenic (Stevenson and Horowitz, 1992) and potentially transmit infectious diseases (Chapman and Villar, 1992). In order to render bone tissue suitable for transplantation, bone banks routinely perform medical screenings as well as a decontamination procedure comprising mechanical and chemical cleansing, freeze-drying and irradiation to eliminate the risk of infection or rejection and to allow storage at room temperature for a prolonged time (Lomas et al., 2000; Scarborough, 1992). However, aside from the practical advantages of allografts, autografts are still the gold standard in bone surgery. This is because the use of allografts for the reconstruction of large skeletal defects is associated with up to $20 \%$ functional graft failure charac- 
terised by stress fractures due to delayed or even missing integration into the recipient's bone tissue (Delloye et al., 2007; Wheeler and Enneking, 2005; Fox et al., 2002; Thompson et al., 1993; Enneking and Mindell, 1991; Berrey et al., 1990; Hornicek et al., 2001). The exact reasons for those complications are not fully understood, but the relation of insufficient or lacking vascularisation of grafts and impaired bone healing has already been discussed (Carano and Filvaroff, 2003; Malloy and Hilibrand, 2002; Stevenson et al., 1996). Many long-term clinical studies assessing the differences in outcome after transplantation of bone auto- vs. allografts have been published (Frances et al., 2007; Deutsch et al., 2007; Gross et al., 2005; Samartzis et al., 2003; McGarvey and Braly, 1996; Mahan and Hillstrom, 1998). Research on the detrimental effect of bone bank processing on the capacity of bone allografts to stimulate blood vessel growth has been scarce and gathered mostly through animal models (Wingenfeld et al., 2002; Egli et al., 2006; Weiland et al., 1984).

In this study, we hypothesised that at least one step of the bone bank procedure reduces the ability of allografts to induce vascularisation. To address this issue we placed human femoral cancellous bone chips representing the different steps of the transplant preparation procedure of a local bone bank onto the chick chorioallantoic membrane (CAM) of fertilised hen's eggs, an established in vivo model for monitoring angiogenesis (Azzarello et al., 2007; Conconi et al., 2005; Staton et al., 2004). Digital images of the CAM at the implantation sites $48 \mathrm{~h}$ after application were used to quantify the vascular reaction. In addition, we determined the vascular reaction of the CAM to allografts that had been stored at $-80^{\circ} \mathrm{C}$ or $+2^{\circ} \mathrm{C}$ for three days prior to implantation.

\section{Materials and methods}

Fresh bone tissue, bone allografts, methylcellulose discs Fresh bone tissue was derived from femoral heads collected in the course of total hip arthroplasty with patients' informed consents (County Hospital Krems, Austria). Four donors were selected according to criteria for tissue acquisition defined and applied by the bone bank (Cells+ Tissuebank Austria, Arthro Kinetics, Krems). Excluded were patients who had taken antiangiogenic drugs or cortisone two weeks prior to surgery as well as patients with a positive HIV or hepatitis status. After removal, the femoral heads were cut into two equal parts, transported to the lab and either stored at $+2^{\circ} \mathrm{C}$ or $-80^{\circ} \mathrm{C}$ for three days. Samples of cancellous bone were taken using a steel puncher and cut to cubic chips of $30 \mathrm{~mm}^{3}$.

Cancellous allograft bone chips were acquired from the local bone bank at different steps of the bone bank's preparation procedure. This comprises mechanical cleaning (step 1), ultrasonification (step 2), chemical cleaning with non-ionic detergents, hydrogen peroxide, and alcohol (step 3), freeze-drying (step 4) and irradiation (step 5). Bone samples representing steps 3 to 5 were stored at $+2^{\circ} \mathrm{C}$, rehydrated with PBS and cut into a quarter of their original size $\left(125 \mathrm{~mm}^{3}\right.$ cubes $)$ prior to the experiment. Samples used for investigations are depicted in Figure 1.
Methylcellulose discs (MC) were used as negative controls and prepared as previously described (Yang and Moses, 1990; Crum et al., 1985). In brief: methylcellulose (Sigma, USA) was suspended at $1 \% \mathrm{w} / \mathrm{v}$ in $\mathrm{ddH}_{2} \mathrm{O}$ under permanent agitation for 24 $\mathrm{h}$. Drops of $10 \mu \mathrm{l}$ of the homogenous suspension were applied onto Petri dishes to allow evaporation of the solvent (3-5 h). The resulting discs ( $3 \mathrm{~mm}$ in diameter) were used for experiments.

\section{In vivo angiogenesis assay using the CAM model}

Fertilised hen's eggs were derived from a poultry farm (Schropper, Austria), washed with warm tap water, disinfected with Sterilium and incubated $\left(37.8^{\circ} \mathrm{C}, 53 \%\right.$ relative humidity, full rotation every $2 \mathrm{~h}$, cooling to $30^{\circ} \mathrm{C}$ once a day for $30 \mathrm{~min}$ ) for $72 \mathrm{~h}$ in an egg incubator (Vario-Lux 128, Heka, Germany). The CAM angiogenesis assay was performed ex ovo as previously described (Ejaz et al., 2004) with some modifications. All manipulations were done under sterile conditions. In brief: After fenestrating the eggshell without injuring the CAM, yolk or embryo, the egg content was transferred into a plastic cup (E71411, Bellaplast, Switzerland). The cups were covered with Petri dishes (BD Falcon, NJ, USA) to prevent dehydration and incubated $\left(37.8^{\circ} \mathrm{C}, 98 \%\right.$ relative humidity, $\left.1 \% \mathrm{CO}_{2}\right)$ in a $\mathrm{CO}_{2}$ incu-

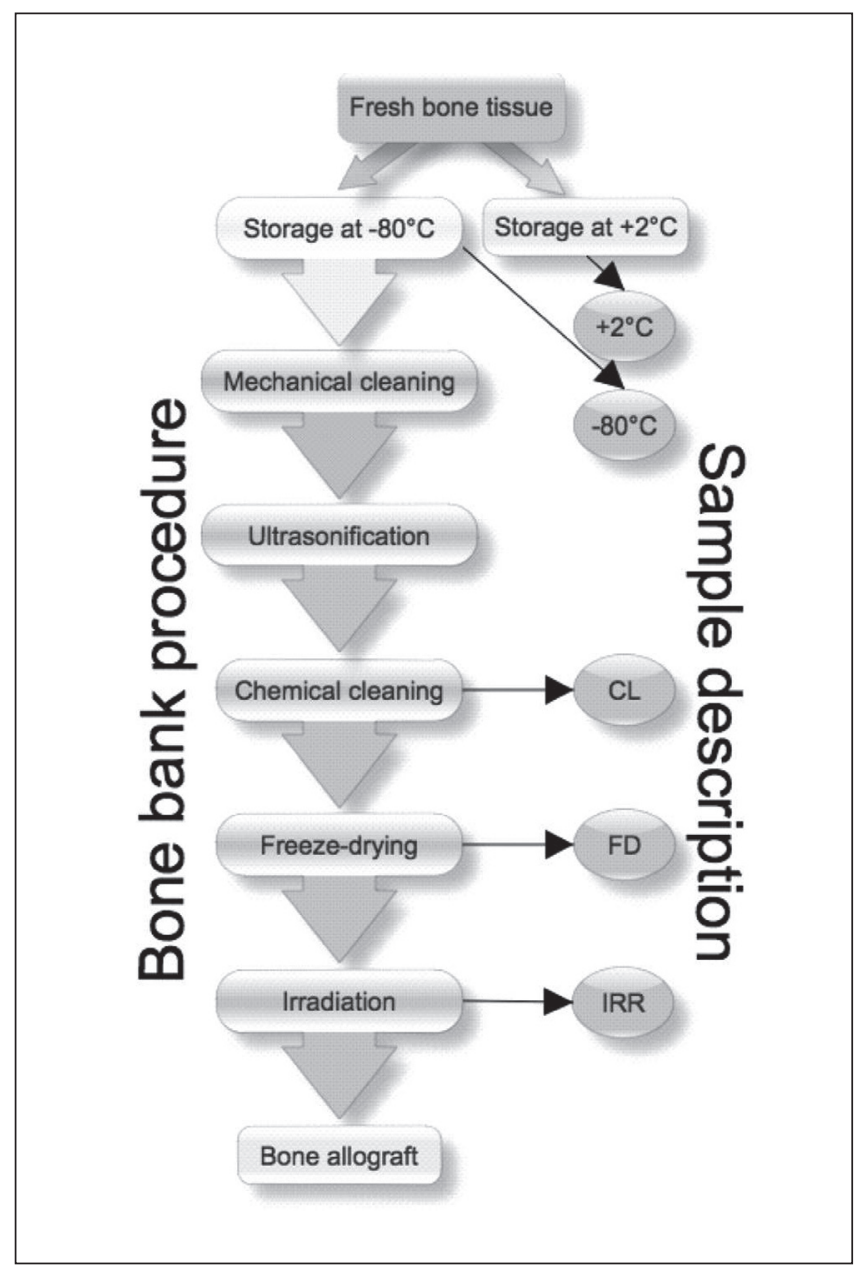

Fig. 1: Outline of the bone bank procedure and sample description. 
bator (Sanyo, Japan) for five days. On day 6 of incubation bone samples and methylcellulose discs were placed onto the CAM and the cups were further incubated for $48 \mathrm{~h}$ followed by the evaluation and histologic examination of the vascular reaction.

The applicability of the CAM model to monitor substanceinduced vascular alterations was validated by using different growth factors and drugs (e.g. bFGF, suramin, hydrocortisone, VEGF) at different concentrations applied via MCs (see above) onto the CAM. Substance-specific and concentration-dependent local (vascularisation) and systemic (viability of the embryos) effects were monitored. The respective buffers used for the solution of substances and for rehydrating bone samples were applied via MCs to monitor unspecific vascular reactions. The buffer controls did not have any effect.

\section{Evaluation of the vascular reaction}

For the semi-quantitative assessment of changes in CAM vascularisation, digital images of samples were assigned to four grades (0-3) by five observers in an independent manner. Images were taken via a stereoscopic microscope (Nikon SMZ645) equipped with a USB camera (CMEX-1, Euromex, Netherlands). The grades were defined as follows (Fig. 2): Grade 0 (no reaction): no changes in density and distribution of vessels compared to control. Grade 1 (weak reaction): a thin vascular rim converges to the bone chip. Grade 2 (medium reaction): up to $50 \%$ of the graft is surrounded by a marked hyperaemia. Grade 3 (strong reaction): blood vessels converge to the graft in a "spoke wheel" manner and/or more than $50 \%$ of the graft is surrounded by a marked hyperaemia or haemorrhage.

The vascular reaction was expressed as vascular index (VI) corresponding to the percentage of the actually determined score related to the maximal attainable score (all images of a type of bone sample assigned to grade 3 ). The final mark of a given bone sample is calculated as the sum of the products of the number of assigned images and the respective grades (0-3).

\section{Histology}

For histochemical analysis bone samples and surrounding CAMs were fixed in $4 \%$ buffered formaldehyde solution (VWR) for 48 h, decalcified via Osteosoft (Merck), dehydrated by serial incubations in alcohol and xylene, embedded in paraffin, sectioned at $5 \mu \mathrm{m}$ and processed for hematoxylin and eosin staining. Images were taken with a Leica microscope DM-1000 and processed using the Leica Image Manager software.

\section{Statistical Analysis}

Means +/- standard deviation were determined for all variables. Four independent trials having at least four replicates per con-

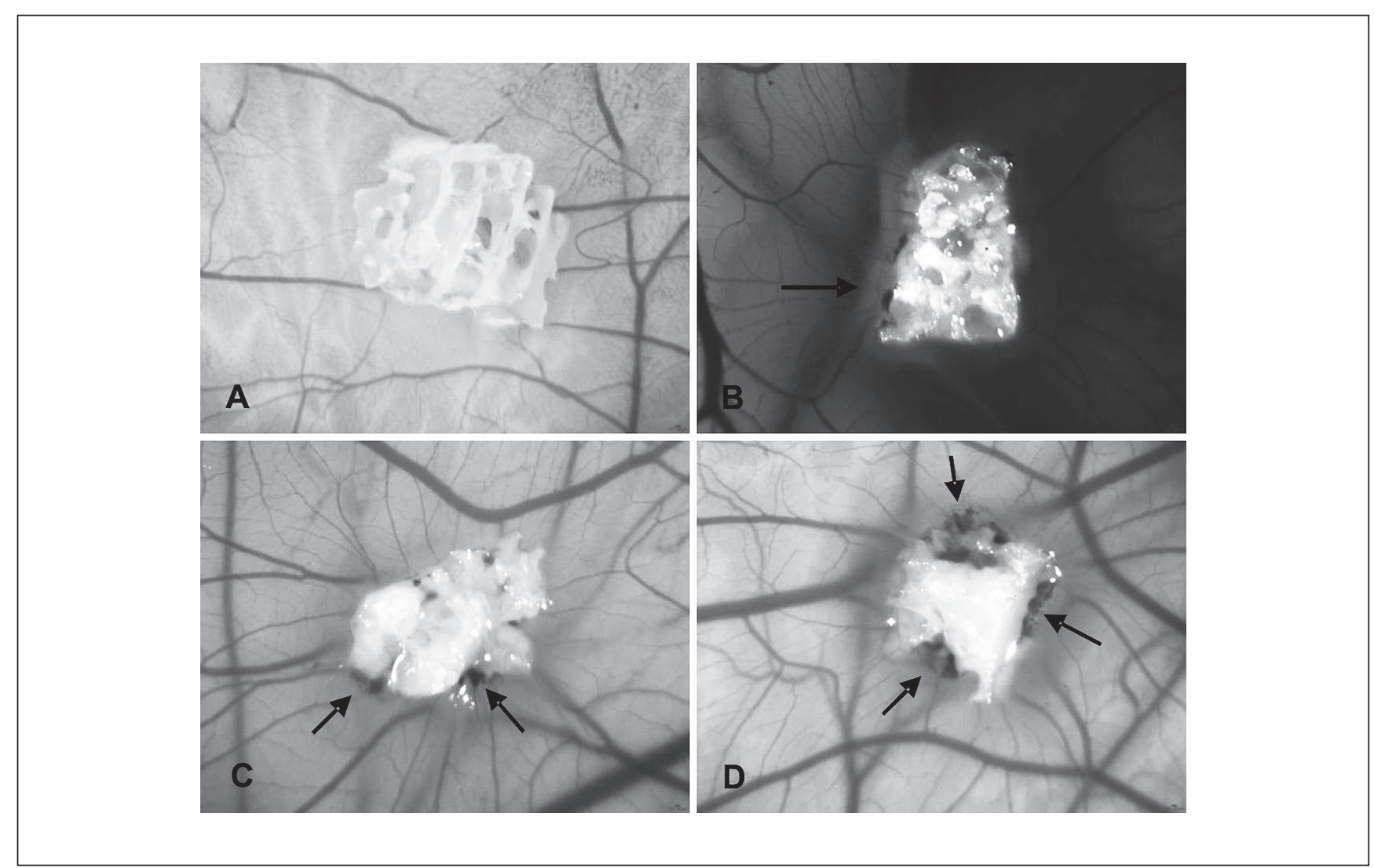

Fig. 2: Examples of vascular reactions of the CAM $48 \mathrm{~h}$ after implantation of bone chips as basis for scoring.

Images were taken at 12X magnification; arrows indicate sites of vascular alterations of the CAM. Score 0: Vessel distribution is similar to that of CAM in the vicinity of control MC pellets (A). Score 1 is given for weak (B), score 2 for medium (C), and score 3 for strong vascular reactions (D). 
dition were performed. Student's $t$ - test was use to assess the significance of the obtained results. $\mathrm{P} \leq 0.05$ values were considered to be statistically significant. All evaluations were performed in a blinded manner.

\section{Results}

Vascular reactions to bone samples

In general, no changes of the vascularisation of the CAM surface were observed during the first $24 \mathrm{~h}$ after implantation of bone samples. The first distinct host reactions with marked hyperaemia and haemorrhages in the immediate vicinity of the implants were seen after $36 \mathrm{~h}$ of incubation. As expected, no reactions of the CAM occurred upon exposure to control MC pellets at any time point.

Bone samples taken after mechanical and chemical cleansing (CL), freeze-drying (FD) or irradiation (IRR) did not show macroscopic alterations of the vascular system of the CAM. However, stereomicroscopic images revealed weak to medium vascular reactions. No grade 3 reaction was recorded in any of these grafts. The overall vascular index accounted for $6.2 \%$, $2.8 \%$, and $5.1 \%$ for samples representing the CD, FD and IRR steps of the bone bank procedure, respectively. Similar results were obtained with fresh bone samples stored at $-80^{\circ} \mathrm{C}$ prior to the experiment. Microscopic examination revealed grade 1 and 2 vascular reactions. The vascular index of $7.45 \%$ was slightly higher than that of processed bone samples although not statistically significant $(\mathrm{p}>0.05)$.

In contrast, fresh bone chips stored at $+2^{\circ} \mathrm{C}$ prior to investigation caused a massive vascular reaction, which was visible even with the naked eye. Under the stereomicroscope, the blood vessels at the immediate rim of these grafts displayed marked hyperaemia and haemorrhages. The overall vascular index of this group was $66.7 \%$ at 48 h (Tab. 1, Fig. 3).

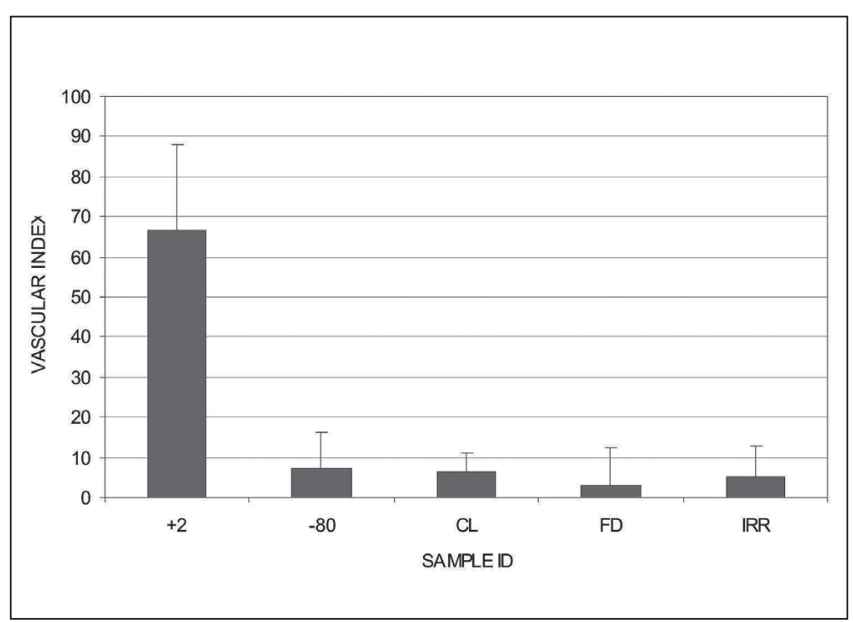

Fig. 3: Vascular indices of the different bone samples.

The vascular indices of different bone samples were calculated as described in materials and methods. The vascular index of sample +2 was significantly higher than those of the other bone samples $(P<0.05)$.

\section{Histological evaluation}

Histologically, the CAM is composed of a layer of chorionic epithelium at its surface, followed by a vascularised mesenchymal stroma and a single layer of allantoic entodermal cells (Wilting et al., 1995; McCormick et al., 1984). Since chick erythrocytes are nucleated, even small capillaries can easily be perceived within the stroma of the CAM. In general, signs of inflammation were not detected in any of the histologic slices.

Histologic slices of fresh, unprocessed cancellous bone samples $\left(+2^{\circ} \mathrm{C}\right)$ revealed a massive hypertrophy of the CAM at the implantation site and an increased number of blood vessels sprouting adjacent to the implants (Fig. 4A). Nevertheless, CAM vessels neither penetrated bone samples nor did we observe a reperfusion of the preexisting graft vasculature.

In accordance with the calculated low vascular index, grafts from the -80 , CL, FD or IRR group induced only slight microscopic changes of the CAM compared with fresh allografts (Fig. 4B).

\section{Discussion}

This paper focuses on the evaluation of the influence of bone bank processing on the angiogenic potency of human bone tissue. Developed during the Second World War as an alternative to fresh autogenous bone, processed bone allografts are nowadays one of the most frequently transplanted tissues and indispensable in orthopaedic surgery (de Boer, 1988).

Recent studies concerning long term follow-up of patients with implanted osteochondral allografts showed that the quality of integration into host tissue is associated with the level of immunological response against the graft and that the reduction of surface antigens through freezing and freezedrying improved the clinical outcome (Friedlaender et al., 1999). Therefore, bare cryopreservation without protective

Tab. 1: Evaluation of the vascular reaction on the CAM $48 \mathrm{~h}$ after implantation of human bone samples.

\begin{tabular}{|l|l|l|l|l|l|}
\hline \multirow{2}{*}{$\begin{array}{l}\text { Bone } \\
\text { samples }\end{array}$} & \multirow{2}{*}{$\begin{array}{l}\text { Number of } \\
\text { evaluated } \\
\text { images }\end{array}$} & \multicolumn{4}{|l|}{ Grades (Scores) } \\
\cline { 3 - 6 } & & $\begin{array}{l}\text { None } \\
(\mathbf{0})\end{array}$ & $\begin{array}{l}\text { Light } \\
\mathbf{( 1 )}\end{array}$ & $\begin{array}{l}\text { Medium } \\
(\mathbf{2})\end{array}$ & $\begin{array}{l}\text { Strong } \\
\mathbf{( 3 )}\end{array}$ \\
\hline+2 & 23 & 19 & 17 & 24 & 55 \\
\hline-80 & 17 & 77 & 2 & 1 & 5 \\
\hline $\mathrm{CL}$ & 15 & 62 & 12 & 1 & 0 \\
\hline FD & 14 & 65 & 4 & 1 & 0 \\
\hline IRR & 17 & 75 & 7 & 3 & 0 \\
\hline
\end{tabular}

$+2=$ fresh cancellous bone stored for 3 days at $+2^{\circ} \mathrm{C}$ prior to implantation;

$-80=$ Fresh cancellous bone stored for 3 days at $-80^{\circ} \mathrm{C}$ prior to implantation;

$\mathrm{CL}=$ cancellous bone chips after mechanical and chemical cleansing;

$\mathrm{FD}=$ cancellous bone chips after freeze-drying;

IRR= cancellous bone chips after irradiation; The vascular reaction was scored by 5 different persons. 

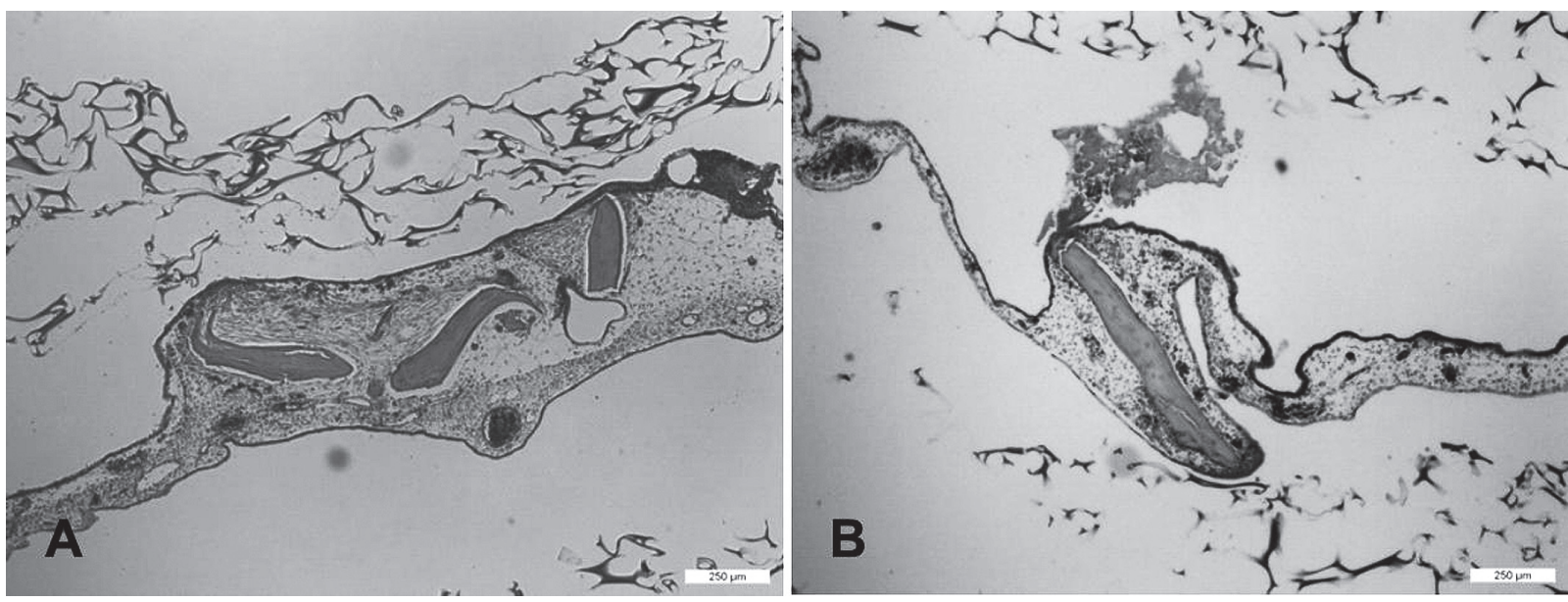

Fig. 4: Histologic slices of the CAM at the sites of implantation of fresh (+2) (A) and frozen bone samples (-80) (B). Images represent slices taken perpendicularly to the CAM surface, stained with hematoxylin and eosin and taken at a magnification of $40 \mathrm{X}$ (scale bar $=250 \mu \mathrm{m}$ ).

substances became a standard procedure in bone banking in the last 30 years.

However, it has been shown that these bone banking procedures compromise the strength (Vastel et al., 2004; Pelker and Friedlaender, 1987), osteoinduction (DePaula et al., 2005; Munting et al., 1988) and biological incorporation of the graft (Hofmann et al., 2005; Burchardt, 1983). Leunig et al. (Leunig et al., 1994 and 1996) demonstrated that mice femora cryopreserved at $-60^{\circ} \mathrm{C}$ with dimethyl sulphoxide (DMSO) retained their angiogenic potential, but only freshly transplanted bone grafts were rapidly reperfused via host-graft anastomosis of blood vessels. Both boiling and unprotected cryopreservation elicited complete loss of cell and organ viability, but boiling additionally caused a loss of angiogenic potency, probably through heat inactivation of growth factors within the bone matrix.

Although our results cannot be automatically extended to grafts of a bigger size or human clinical trials, we assume that the observed vascular reaction of the CAM reflects the osteoinductive potency of the graft, which has a close relationship to its revascularisation and, hence, bone healing.

In our findings, a strong overall vascular response was observed only when fresh cancellous bone chips from human femoral heads were used. Stored for three days at $+2^{\circ} \mathrm{C}$, they retained their full osteoinductive potency to induce the first step of vascularisation through stimulation of host blood vessel growth at the implantation area. In contrast, bare freezing of the femoral heads to $-80^{\circ} \mathrm{C}$ for three days caused a significant reduction of early vascularisation, a sign of impairment of the biological function of the graft. The observed haemorrhages seen in the immediate vicinity of these two graft groups, although at different frequencies, are assumed to result from leakage of immature blood vessels. Their late appearance $48 \mathrm{~h}$ after implantation makes it unlikely that they are the result of simple mechanical tissue damage.
When bone chips from the later stages of allograft production (CL, FD or IRR) were used, a further reduction of the vascular index compared to the previous groups was found. This can on one hand be attributed to the numerous steps of industrial bone bank processing. Considering that femoral heads are kept frozen at $-80^{\circ} \mathrm{C}$ for up to one month before further handling, adverse effects from this measure possibly contribute to the negative overall result of this study group.

Our histological slices showed an increase of blood vessel sprouts only around the fresh cancellous bone chips, with no blood vessels growing into the bone. Furthermore, reperfusion of the existing vasculature, as a sign of graft-host blood vessel anastomosis, was not observed either. These results are consistent with the literature: (1) it takes up to a week for blood vessels to grow within acellular bone chips (Deleu and Trueta, 1965), and (2) vascularisation of living tissue placed on the CAM is not observed until the third day after implantation (except for autogenous chick embryonic tissue) (Ausprunk et al., 1975).

In conclusion, we demonstrate that storage of bone samples at $-80^{\circ} \mathrm{C}$ prior to the bone bank procedure is the crucial step that diminishes the angiogenic potential of bone samples in the CAM model. Taking into account that the $+2{ }^{\circ} \mathrm{C}$ sample most possibly reflects the biological status of autogeneic transplants better than the allogeneic samples (-80, CL, FD and IRR), our results support the common view of autogeneic transplantation as gold standard for the treatment of large bone defects.

\section{References}

Aro, H. T. and Aho, A. J. (1993). Clinical use of bone allografts. Ann. Med. 25(4), 403-412.

Ausprunk, D. H., Knighton, D. R. and Folkman, J. (1975). Vascularization of normal and neoplastic tissues grafted to the 
chick chorioallantois. Role of host and preexisting graft blood vessels. Am. J. Pathol. 79(3), 597-618.

Azzarello, J., Ihnat, M. A., Kropp, B. P. et al. (2007). Assessment of angiogenic properties of biomaterials using the chicken embryo chorioallantoic membrane assay. Biomedical Materials 2, 55-61.

Berrey, B. H. Jr., Lord, C.F., Gebhardt, M. C. and Mankin, H. J. (1990). Fractures of allografts. Frequency, treatment, and end-results. J. Bone Joint Surg. Am. 72(6), 825-833.

Burchardt, H. (1983). The biology of bone graft repair. Clin. Orthop. Relat. Res. (174), 28-42.

Carano, R. A. and Filvaroff, E. H. (2003). Angiogenesis and bone repair. Drug Discov. Today 8(21), 980-989.

Carmeliet, P. (2004). Manipulating angiogenesis in medicine. $J$. Intern. Med. 255(5), 538-561.

Chapman, P. G. and Villar, R. N. (1992). The bacteriology of bone allografts. J. Bone Joint Surg. Br. 74(3), 398-399.

Conconi, M. T., Nico, B., Rebuffat, P. et al. (2005). Angiogenic response induced by acellular femoral matrix in vivo. J. Anat. 207(1), 79-83.

Crum, R., Szabo, S. and Folkman, J. (1985). A new class of steroids inhibits angiogenesis in the presence of heparin or a heparin fragment. Science 230(4732), 1375-1378.

de Boer, H. H. (1988). The history of bone grafts. Clin. Orthop. Relat. Res. (226), 292-298.

Deleu, J. and Trueta, J. (1965). Vascularisation of Bone Grafts in the Anterior Chamber of the Eye. J. Bone Joint Surg. Br. 47, 319-329.

Delloye, C., Cornu, O., Druez, V. and Barbier, O. (2007). Bone allografts: What they can offer and what they cannot. J. Bone Joint Surg. Br. 89(5), 574-579.

DePaula, C. A., Truncale, K. G., Gertzman, A. A. et al. (2005). Effects of hydrogen peroxide cleaning procedures on bone graft osteoinductivity and mechanical properties. Cell Tissue Bank 6(4), 287-298.

Deutsch, H., Haid, R., Rodts, G. Jr. and Mummaneni, P. V. (2007). The decision-making process: allograft versus autograft. Neurosurgery 60(1 Supp1 1), S98-102.

Egli, R. J., Wingenfeld, C., Holzle, M. et al. (2006). Histopathology of cryopreserved bone allo- and isografts: pretreatment with dimethyl sulfoxide. J. Invest. Surg. 19(2), 87-96.

Ejaz, S., Seok, K. B. and Woong, L. C. (2004). A novel image probing system for precise quantification of angiogenesis. Tumori 90(6), 611-617.

Enneking, W. F. and Mindell, E. R. (1991). Observations on massive retrieved human allografts. J. Bone Joint Surg. Am. 73(8), 1123-1142.

Finkemeier, C. G. (2002). Bone-grafting and bone-graft substitutes. J. Bone Joint Surg. Am. 84-A(3), 454-464.

Fox, E. J., Hau, M. A., Gebhardt, M. C. et al. (2002). Long-term followup of proximal femoral allografts. Clin. Orthop. Relat. Res. (397), 106-113.

Frances, A., Moro, E., Cebrian, J. L. et al. (2007). Reconstruction of bone defects with impacted allograft in femoral stem revision surgery. Int. Orthop. 31(4), 457-464.
Friedlaender, G. E., Strong, D. M., Tomford, W. W. and Mankin, H. J. (1999). Long-term follow-up of patients with osteochondral allografts. A correlation between immunologic responses and clinical outcome. Orthop. Clin. North Am. 30(4), 583588.

Gross, A. E., Shasha, N. and Aubin, P. (2005). Long-term followup of the use of fresh osteochondral allografts for posttraumatic knee defects. Clin. Orthop. Relat. Res. (435), 7987.

Gross, T. P., Cox, Q. G. and Jinnah, R. H. (1993). History and current application of bone transplantation. Orthopedics 16(8), 895-900.

Hofmann, A., Konrad, L., Hessmann, M. H. et al. (2005). The influence of bone allograft processing on osteoblast attachment and function. J. Orthop. Res. 23(4), 846-854.

Hornicek, F. J., Gebhardt, M. C., Tomford, W. W. et al. (2001). Factors affecting nonunion of the allograft-host junction. Clin. Orthop. Relat. Res. (382), 87-98.

Huo, M. H., Friedlaender, G. E. and Salvati, E. A. (1992). Bone graft and total hip arthroplasty. A review. J. Arthroplasty 7(2), 109-120.

Leunig, M., Yuan, F., Berk, D. A. et al. (1996). Heating or freezing bone. Effects on angiogenesis induction and growth potential in mice. Acta Orthop. Scand. 67(4), 383-388.

Leunig, M., Yuan, F., Berk, D. A. et al. (1994). Angiogenesis and growth of isografted bone: quantitative in vivo assay in nude mice. Lab. Invest. 71(2), 300-307.

Lomas, R., Drummond, O. and Kearney, J. N. (2000). Processing of whole femoral head allografts: a method for improving clinical efficacy and safety. Cell Tissue Bank 1(3), 193-200.

Mahan, K. T. and Hillstrom, H. J. (1998). Bone grafting in foot and ankle surgery. A review of 300 cases. J. Am. Podiatr. Med. Assoc. 88(3), 109-118.

Malloy, K. M. and Hilibrand, A. S. (2002). Autograft versus allograft in degenerative cervical disease. Clin. Orthop. Relat. Res. (394), 27-38.

McCormick, J. F., Nassauer, J., Bielunas, J. and Leighton, J. (1984). Anatomy of the chick chorioallantoic membrane relevant to its use as a substrate in bioassay systems. Scan.Electron. Microsc. (Pt 4), 2023-2030.

McGarvey, W. C. and Braly, W. G. (1996). Bone graft in hindfoot arthrodesis: allograft vs autograft. Orthopedics 19(5), 389-394.

Munting, E., Wilmart, J. F., Wijne, A. et al. (1988). Effect of sterilization on osteoinduction. Comparison of five methods in demineralized rat bone. Acta Orthop. Scand. 59(1), 34-38.

Pelker, R. R. and Friedlaender, G. E. (1987). Biomechanical aspects of bone autografts and allografts. Orthop. Clin. North Am. 18(2), 235-239.

Probst, A. and Spiegel, H. U. (1997). Cellular mechanisms of bone repair. J. Invest. Surg. 10(3), 77-86.

Samartzis, D., Shen, F. H., Matthews, D. K. et al. (2003). Comparison of allograft to autograft in multilevel anterior cervical discectomy and fusion with rigid plate fixation. Spine J. 3(6), 451-459. 
Scarborough, N. L. (1992). Current procedures for banking allograft human bone. Orthopedics 15(10), 1161-1167.

Staton, C. A., Stribbling, S. M., Tazzyman, S. et al. (2004). Current methods for assaying angiogenesis in vitro and in vivo. Int. J. Exp. Pathol. 85(5), 233-248.

Stevenson, S., Emery, S. E. and Goldberg, V. M. (1996). Factors affecting bone graft incorporation. Clin. Orthop. Relat. Res. (324), 66-74.

Stevenson, S. and Horowitz, M. (1992). The response to bone allografts. J. Bone Joint Surg. Am. 74(6), 939-950.

Thompson, R. C. Jr., Pickvance, E. A. and Garry, D. (1993). Fractures in large-segment allografts. J. Bone Joint Surg. Am. 75(11), 1663-1673.

Vastel, L., Meunier, A., Siney, H. et al. (2004). Effect of different sterilization processing methods on the mechanical properties of human cancellous bone allografts. Biomaterials 25(11), 2105-2110.

Weiland, A. J., Phillips, T. W. and Randolph, M. A. (1984). Bone grafts: a radiologic, histologic, and biomechanical model comparing autografts, allografts, and free vascularized bone grafts. Plast Reconstr. Surg. 74(3), 368-379.

Wheeler, D. L. and Enneking, W. F. (2005). Allograft bone decreases in strength in vivo over time. Clin. Orthop. Relat. Res. (435), 36-42.

Wilting, J., Brand-Saberi, B., Kurz, H. and Christ, B. (1995).
Development of the embryonic vascular system. Cell Mol. Biol. Res. 41(4), 219-232.

Wingenfeld, C., Egli, R. J., Hempfing, A. et al. (2002). Cryopreservation of osteochondral allografts: dimethyl sulfoxide promotes angiogenesis and immune tolerance in mice. $J$. Bone Joint Surg. Am. 84-A(8), 1420-1429.

Yang, E. Y. and Moses, H. L. (1990). Transforming growth factor beta 1 -induced changes in cell migration, proliferation, and angiogenesis in the chicken chorioallantoic membrane. $J$. Cell Biol. 111(2), 731-741.

\section{Acknowledgement}

This project was funded by a grant from the Austrian Society for Orthopaedic Surgery (ÖGO).

\section{Correspondence to}

Mag. Hannes Zwickl

Center for Regenerative Medicine

Dept. for Clinical Medicine and Biotechnology

Danube University Krems

Dr. Karl-Dorrek-Straße 30

3500 Krems, Austria

e-mail: hannes.zwick1@donau-uni.ac.at 